\title{
Associations of airway tree to lung volume ratio on computed tomography with lung function and symptoms in chronic obstructive pulmonary disease
}

Naoya Tanabe ${ }^{* \dagger}$ (D) Susumu Sato ${ }^{\dagger}$, Tsuyoshi Oguma, Hiroshi Shima, Atsuyasu Sato, Shigeo Muro and Toyohiro Hirai

\begin{abstract}
Background: Decreased airway lumen size and increased lung volume are major structural changes in chronic obstructive pulmonary disease (COPD). However, even though the outer wall of the airways is connected with lung parenchyma and the mechanical properties of the parenchyma affect the behaviour of the airways, little is known about the interactions between airway and lung sizes on lung function and symptoms. The present study examined these effects by establishing a novel computed tomography $(\mathrm{CT})$ index, namely, airway volume percent (AWV\%), which was defined as a percentage ratio of the airway tree to lung volume.
\end{abstract}

Methods: Inspiratory chest CT, pulmonary function, and COPD Assessment Tests (CAT) were analysed in 147 stable males with COPD. The whole airway tree was automatically segmented, and the percentage ratio of the airway tree volume in the right upper and middle-lower lobes to right lung volume was calculated as the AWV\% for right lung. Low attenuation volume \% (LAV\%), total airway count (TAC), luminal area (Ai), and wall area percent (WA\%) were also measured.

Results: AWV\% decreased as the Global Initiative for Chronic Obstructive Lung Disease (GOLD) spirometric grade increased $(p<0.0001)$. AWV\% was lower in symptomatic (CAT score $\geq 10$ ) subjects than in non-symptomatic subjects $(p=0.036)$. AWV\% was more closely correlated with forced expiratory volume in $1 \mathrm{~s}\left(\mathrm{FEV}_{1}\right)$ and ratio of residual volume to total lung capacity (RV/TLC) than $\mathrm{Ai}$, $\mathrm{Ai}$ to lung volume ratio, and volume of either the lung or the airway tree. Multivariate analyses showed that lower AWV\% was associated with lower FEV 1 and higher RV/TLC, independent of LAV\%, WA\%, and TAC.

Conclusions: A disproportionally small airway tree with a relatively large lung could lead to airflow obstruction and gas trapping in COPD. AWV\% is an easily measured CT biomarker that may elucidate the clinical impacts of the airway-lung interaction in COPD.

Keywords: Chronic obstructive pulmonary disease, Computed tomography, Airway, Pulmonary function, Emphysema, Symptom

\footnotetext{
* Correspondence: ntana@kuhp.kyoto-u.ac.jp

${ }^{\dagger}$ Naoya Tanabe and Susumu Sato contributed equally to this work.

Department of Respiratory Medicine, Graduate School of Medicine, Kyoto

University, 54 Kawahara-cho, Shogoin, Sakyo-ku, Kyoto 606-8507, Japan
}

(c) The Author(s). 2019 Open Access This article is distributed under the terms of the Creative Commons Attribution 4.0 International License (http://creativecommons.org/licenses/by/4.0/), which permits unrestricted use, distribution, and reproduction in any medium, provided you give appropriate credit to the original author(s) and the source, provide a link to the Creative Commons license, and indicate if changes were made. The Creative Commons Public Domain Dedication waiver (http://creativecommons.org/publicdomain/zero/1.0/) applies to the data made available in this article, unless otherwise stated. 


\section{Background}

Chronic obstructive pulmonary disease (COPD) is characterized by expiratory airflow obstruction that is caused by a combination of emphysematous destruction of the parenchyma and disease of the small airways [1]. Because obtaining pathological samples of lung tissue is too invasive to perform in clinical practice, chest computed tomography (CT) has been used to obtain separate estimations of these two pathological lesions [2]. Emphysematous changes measured by $\mathrm{CT}$ is associated with worsening of lung function [3] and symptoms [4], frequent exacerbation [5], and poor prognosis [6]. In addition, loss of elastic recoil due to emphysema causes lung hyper-expansion that can also be quantified as total lung volume in CT [7]. The CT-measured total lung volume has been used for evaluating the effects of pharmacological, bronchoscopic, and surgical lung volume reduction, as well as lung growth [8-11].

Although small airways cannot be visualized by CT due to the resolution limitation $[3,12]$, measurements of the central airway dimensions are informative because these dimensions reflect the histological features of small airway disease [13]. In particular, a small airway lumen area in COPD is an important CT finding that is closely correlated with airflow obstruction, as assessed by forced expiratory volume in $1 \mathrm{~s}\left(\mathrm{FEV}_{1}\right)[14,15]$ and gas trapping, as assessed by residual volume (RV), or its ratio to total lung capacity (TLC) [RV/TLC] [7]. Moreover, these smaller lumens of the airways reduce the number of airways visible on $\mathrm{CT}$, and this impaired visibility is currently assessed as total airway count (TAC) [16], which has been shown to be associated with $\mathrm{FEV}_{1}$, dyspnoea, exercise tolerance and future lung function decline $[16,17]$.

Since the outer wall of the airways is connected with the lung parenchyma, the mechanical properties of the parenchyma affect the behaviour of the airways [18]. This airway-parenchyma interdependence allows the elastic recoil of the lung to maintain airway calibre, indicating that any disease condition inducing loss of elastic recoil could reduce airway calibre [19]. Indeed, histological and microCT analyses have shown that loss of the alveolar attachments to the outer wall of the small airways is closely correlated with lumen narrowing in emphysema [20-22]. A CT study by Diaz et al. [23] also showed that segmental and subsegmental airways are distended during breathing up to the TLC level in healthy lungs, but this distensibility is diminished in hyper-inflated emphysematous lung and further reduction of the lumen area occurs at full inspiration. Moreover, physiological and CT imaging studies have shown that the association between airway and lung sizes is not constant even in healthy subjects [24, 25], and suggested that dysanaptic lung growth that is characterized by an increase in lung size without change in airway size in early life might impair lung function [9, 25], supporting a recent notion that abnormal lung growth potentially affects COPD development [26]. However, little is still known about the interaction between airway and lung sizes on lung function and symptoms in COPD.

It was hypothesized that a reduction in the ratio of airway tree volume to lung volume could be a major determinant of impaired pulmonary function and clinical symptoms in COPD. To test this hypothesis, the present study aimed to establish a novel CT marker, namely, airway volume percent (AWV\%), that was defined as a percentage ratio of the airway tree volume to the entire lung volume and to explore the associations of the AWV\% with lung function and symptoms assessed by the COPD Assessment Test (CAT).

\section{Methods \\ Ethics}

This study was performed in accordance with the Declaration of Helsinki. This human study was approved by the Ethics Committee of Kyoto University (approval No. E182). Written informed consent was obtained from all participants.

\section{Study subjects}

The data used in the present analysis were based on those from a prospective observational study performed at Kyoto University $[27,28]$. The inclusion criteria were (1) a smoking history of at least 20 pack-years, (2) COPD diagnosis, and (3) no history of lung resection surgery or other lung diseases, such as bronchial asthma or interstitial lung disease. All male patients who underwent chest inspiratory CT scans and completed lung function testing including spirometry, lung volumes and diffusion capacity measurements, and a CAT questionnaire during an exacerbation-free period were enrolled at Kyoto University Hospital from April 2011 to April 2014. Lung function was measured with a Chestac-65 V (Chest MI Corp., Tokyo, Japan), and chest CT scans were performed with an Aquilion 64 scanner (Toshiba; Tokyo, Japan). Calibration of the CT scanner was routinely performed with air and water phantoms, and the scanning conditions were as follows: $0.5-\mathrm{mm}$ collimation, 500-millisecond scan time, 120 peak kilovoltage, and auto-exposure control. Reconstruction was performed with a high spatial frequency algorithm (FC56) as previously reported [27].

\section{$\mathrm{CT}$ analysis}

\section{Airway volume percent (AWV\%)}

To evaluate the volume of the airways visible on CT images (Additional file 1: Figure S1A), the entire airway 
tree was automatically segmented without any manual editing using a SYNAPSE VINCENT volume analyser Ver5.3 (FUJIFILM Medical, Tokyo, Japan). The segmented airway trees were exported as DICOM files and further segmented into portions of the right upper lobe (RUL), right middle-lower lobe (RMLL), and the remaining lobes with ITK-SNAP software (Additional file 1: Figure S1B) [29]. The airway tree in the left lung was not used because segmentation of this area could be affected by cardiac motion artefacts. The volumes of the RUL and RMLL were added to obtain the total airway volume in the right lung (AWV). Right lung volume (rLV) was also measured, and the airway volume percent (AWV\%) was calculated with the following formula: $\mathrm{AWV} \%=100 * \mathrm{AWV} / \mathrm{rLV}$ using custom software. Because the luminal size of the central airways was affected by the natural size of the lungs, the predicted total lung capacity (pTLC) was calculated [30] for adjustment of the AWV and right lung volume.

\section{Total airway count (TAC)}

Following the segmentation of the airway trees in the RUL and RMLL, these segmented trees were skeletonized to obtain their centre lines using custom software. Each branch of the centre line between branching points was labelled. Based on this labelling, the airway trees in the RUL and RMLL were separated into branches, and all the branched trees were labelled (Additional file 1: Figure S1C). Corrections of labels were performed manually when necessary.

\section{Luminal area (Ai) and wall area percent (WA\%)}

Using the custom software, the lumen and wall of the right apical and lower posterior segmental and sub-segmental airways (RB1 and RB10 paths) were segmented with the full-width half-maximum principle as reported previously $[3,31]$. The lumen area $(\mathrm{Ai})$ and wall area (WA) were measured, and then, the wall area percent (WA\%) was calculated using the following formula: 100*WA / (sum of Ai and WA). The average Ai and WA\% from RB1 and RB10 were used for the present analyses.

\section{Low attenuation volume percent (LAV\%)}

Using the SYNAPSE VINCENT volume analyser, lung volume (CT-TLV) and the percentage ratio of voxels < $-950 \mathrm{HU}$ to the entire lung voxels, namely, the low attenuation volume percent (LAV\%), for both lungs and the right lung alone were measured [8, 16, 27, 32-34].

\section{Statistics}

The data are expressed as the mean \pm standard deviation (SD). Pearson correlation analysis was used to evaluate associations among $\mathrm{CT}$ measures and pulmonary function. Multivariate linear regression analysis including CT indices, age, body mass index (BMI), and smoking pack-years as independent variables and each pulmonary function value as dependent variables was performed. Statistical analysis was performed with $\mathrm{R}$ [35]. A $p$-value less than 0.05 was considered statistically significant.

\section{Results}

The basic data of study subjects are summarized in Table 1. Figure 1 shows representative 3D renderings of the airway tree and the right lung in COPD subjects with mild and severe airflow obstruction (cases A and B, $\% \mathrm{FEV} 1=81$ and $31 \%$, respectively). Although there was no difference in height (both $167 \mathrm{~cm}$ ), the AWV was smaller (9 vs $18 \mathrm{ml}$ ) and right lung volume was larger (2998 vs $2519 \mathrm{ml}$ ) in case B than Case A, which made a substantial difference in the AWV\% between the two cases.

Data are expressed as the mean $\pm \mathrm{SD}$. BMI body mass index, $F E V_{1}$ forced expiratory volume in $1 \mathrm{~s}, F V C$ forced vital capacity, $R V / T L C$ residual volume / total lung capacity, $D_{L C O}$ diffusion capacity, CAT COPD Assessment Test, $L A V \%$ low attenuation volume percent, $W A \%$ wall area percent, $T A C$ total airway count.

Figure 2 shows that the AWV/pTLC decreased (A), $\mathrm{rLV} / \mathrm{pTLC}$ increased (B) (both $p<0.001$ by ANOVA), and the AWV\% decreased as the Global Initiative for Chronic Obstructive Lung Disease (GOLD) spirometric grade increased $(C)(p<0.001)$. The AWV\% was also lower in symptomatic (CAT score $\geqq 10$ ) subjects than non-symptomatic subjects $(0.50 \pm 0.12 \%$ and 0.55 $\pm 0.15 \%$, respectively, $p=0.036$, Additional file 1 : Figure S2).

Table 1 Patient demographics $(n=147)$

\begin{tabular}{ll}
\hline Age & $71 \pm 9$ \\
\hline Sex & All male \\
BMI & $22 \pm 3$ \\
Smoking pack-years & $63 \pm 35$ \\
FEV $_{1}$ (\% predicted) & $61 \pm 20$ \\
FEV 1 /FVC (\%) & $51 \pm 13$ \\
RV/TLC (\%) & $42 \pm 7$ \\
TLC (\% predicted) & $96 \pm 13$ \\
D LCO (\% predicted) & $53 \pm 14$ \\
CAT sCore \10 [n (\%)] & $81(55 \%)$ \\
LAV\% & $29 \pm 9$ \\
WA\% (segmental airways) & $58 \pm 5$ \\
WA\% (sub-segmental airways) & $64 \pm 4$ \\
TAC (right lung) & $212 \pm 51$ \\
\hline
\end{tabular}



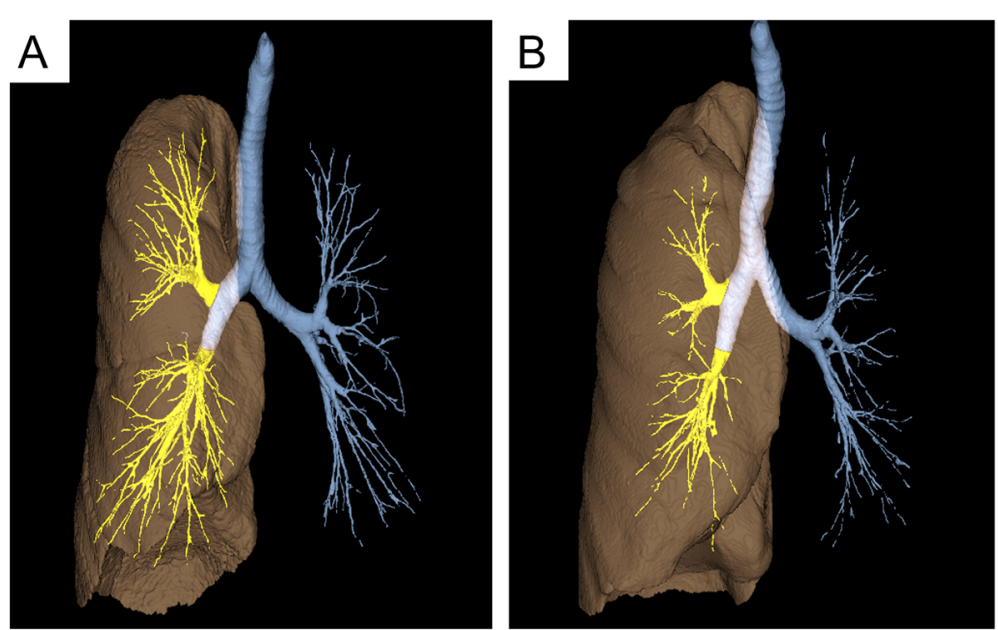

Fig. 1 Representative 3D renderings of airway tree and right lung in 2 COPD cases. A percentage ratio of airway tree volume in the right upper and middle-lower lobes (AWV, highlighted by yellow colour) to the right lung volume (rLV, brown colour), namely, the airway volume percent (AWV\%), was compared between COPD subjects with mild airflow obstruction (Case A, \%FEV $1=81 \%$, height $=167 \mathrm{~cm}$ ) and with severe airflow obstruction (Case B, \%FEV $1=32 \%$, height $=167 \mathrm{~cm}$ ). Compared to Case $\mathrm{A}(\mathrm{AWV}=18 \mathrm{ml}, \mathrm{rLV}=2519 \mathrm{ml})$, Case B showed smaller airway tree volume and larger lung volume (AWV $=9 \mathrm{ml}, \mathrm{rLV}=2998 \mathrm{ml})$, which resulted in substantially lower AWV\%

$A i$ luminal area of subsegmental airways, $p T L C$ predicted TLC, $r L V$ right lung volume, $A W V$ airway volume, $A W V \%$ airway volume percent, $L A V \%$ low attenuation volume percent, $F E V_{1}$ forced expiratory volume in $1 \mathrm{~s}, R V / T L C$ residual volume / total lung capacity, $D_{L C O}$ diffusion capacity. ${ }^{\mathrm{a}}$ and ${ }^{\mathrm{b}}$ indicate $p<0.05$ and $p<0.005$, respectively

The Pearson correlation tests (Table 2 and Fig. 3) showed that $\mathrm{Ai}, \mathrm{Ai} /(\mathrm{pTLC})^{2 / 3}, \mathrm{Ai} /(\mathrm{rLV})^{2 / 3}, \mathrm{rLV}, \mathrm{rLV} /$ pTLC, AWV, AWV/pTLC, and AWV\% as well as LAV\% were all correlated with $\mathrm{FEV}_{1}, \% \mathrm{FEV}_{1}$, and RV/TLC. Based on the correlation coefficients, the extent of the correlations in AWV\% was higher than in the other measures of the airway and lung sizes, and similar to that in LAV\%. Moreover, Table 2 and Additional file 1: Figure S3 show that LAV\%, but not AWV\%, was associated with $\% \mathrm{D}_{\mathrm{LCO}}$ and $\mathrm{D}_{\mathrm{LCO}} / \mathrm{V}_{\mathrm{A}}$ while both the indexes were correlated with \%TLC. Additional file 1: Figure S4 shows associations of AWV\% with TAC, WA\%, and LAV\%.

In multivariate analyses (Table 3), AWV\% was significantly associated with \% $\mathrm{FEV}_{1}$ and RV/TLC independent of LAV\%, WA\%, and TAC. Additional file 1: Table S1 shows that the multivariate model including both AWV\% and LAV\% as independent variables accounted for more variations of $\% \mathrm{FEV}_{1}$ and $\mathrm{RV} / \mathrm{TLC}\left(\mathrm{R}^{2}=0.47\right.$ and 0.38 , respectively) compared to the models including either AWV\% $\left(R^{2}=0.34\right.$ and 0.34 , respectively) or LAV\% $\left(R^{2}=0.21\right.$ and 0.22 , respectively).

$F E V_{1}$ forced expiratory volume in $1 \mathrm{~s}, R V / T L C$ residual volume / total lung capacity, $L A V \%$ low attenuation volume percent, $W A \%$ wall area percent, $T A C$ total airway count, and $A W V \%$ airway volume percent. $\beta^{\mathrm{a}}$ indicates standardized $\beta .^{\mathrm{b}}$ adjusted by age, BMI, pack-years, and CT-measured total lung volume. VIF indicates variance inflation factor
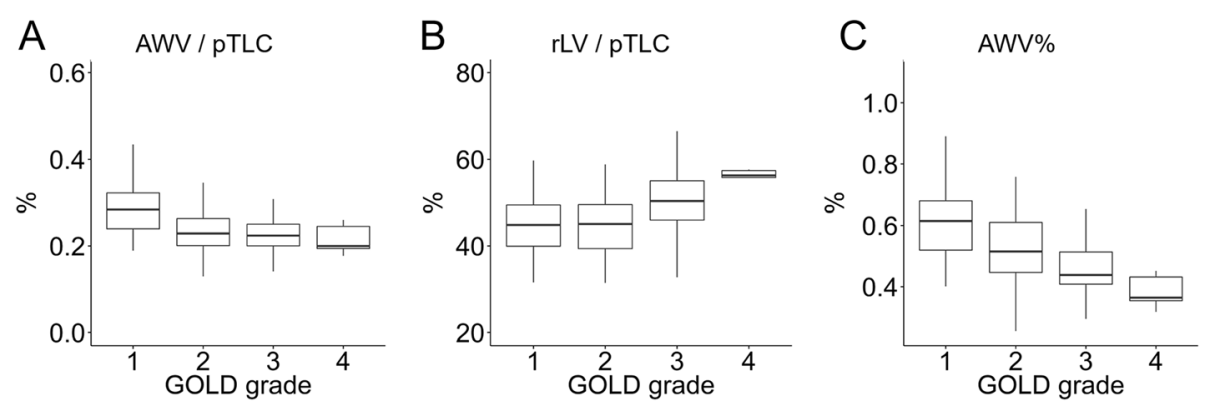

Fig. 2 Airway and lung measures and severity of COPD (A and B) The airway wall volume (AWM) and right lung volume (rLV) are adjusted by the predicted total lung capacity (pTLC). (C) The airway wall volume percent (AW\%) was the percentage ratio of the AWW to right lung volume. Statistical analysis with ANOVA showed significant differences in AW/pTLC $(p=0.00001)$, rLV/pTLC $(p=0.00001)$, and AWW\% $(P=0.000001)$ among different GOLD spirometric grade 
Table 2 Pearson correlation coefficients between airway and lung size indices, emphysema severity, and physiological measurements

\begin{tabular}{lllll}
\hline & $\mathrm{FEV}_{1}(\mathrm{~L})$ & $\% \mathrm{FEV}_{1}(\%)$ & $\mathrm{RV} / \mathrm{TLC}(\%)$ & $\% \mathrm{DLCO}_{\mathrm{LCO}}(\%)$ \\
\hline Lumen area & & & & \\
$\mathrm{Ai}\left(\mathrm{mm}^{2}\right)$ & $0.27^{\mathrm{b}}$ & $0.24^{\mathrm{b}}$ & $-0.24^{\mathrm{b}}$ & -0.05 \\
$\mathrm{Ai} /(\mathrm{pTLC})^{2 / 3}(\%)$ & $0.16^{\mathrm{a}}$ & $0.18^{\mathrm{a}}$ & $-0.19^{\mathrm{a}}$ & -0.09 \\
$\mathrm{Ai} /(\mathrm{rLV})^{2 / 3}(\%)$ & $0.31^{\mathrm{b}}$ & $0.32^{\mathrm{b}}$ & $-0.33^{\mathrm{b}}$ & 0.01 \\
Lung volume & & & & \\
rLV (ml) & -0.14 & $-0.21^{\mathrm{a}}$ & $0.22^{\mathrm{a}}$ & -0.12 \\
$\mathrm{rLV} / \mathrm{pTLC}(\%)$ & $-0.37^{\mathrm{b}}$ & $-0.35^{\mathrm{b}}$ & $0.33^{\mathrm{b}}$ & $-0.21^{\mathrm{a}}$ \\
Airway tree volume & & & & \\
AWV (ml) & $0.41^{\mathrm{b}}$ & $0.43^{\mathrm{b}}$ & $-0.35^{\mathrm{b}}$ & 0.00 \\
AWV / pTLC (\%) & $0.27^{\mathrm{b}}$ & $0.36^{\mathrm{b}}$ & $-0.29^{\mathrm{b}}$ & -0.06 \\
AWV\% (\%) & $0.48^{\mathrm{b}}$ & $0.56^{\mathrm{b}}$ & $-0.47^{\mathrm{b}}$ & 0.07 \\
Emphysema & & & & \\
LAV\% & $-0.48^{\mathrm{b}}$ & $-0.48^{\mathrm{b}}$ & $0.43^{\mathrm{b}}$ & $-0.62^{\mathrm{b}}$ \\
\hline
\end{tabular}

\section{Discussion}

This is the first study to assess the interaction of three-dimensionally measured airway tree and lung volumes on lung function and symptoms in COPD. Although many CT studies have shown that small lumen
Table 3 Multivariate linear regression analysis to explore the associations between $\mathrm{CT}$ indices and pulmonary function

\begin{tabular}{lllll}
\hline Model 1 (\%FEV $)^{\text {b }}$ & & $\beta^{\text {a }}$ & VIF & $p$ value \\
\hline & LAV\% & -0.50 & 2.3 & $<0.00001$ \\
& WA\% & -0.26 & 1.6 & 0.73 \\
& TAC & 0.21 & 3.2 & 0.048 \\
& AWV\% & 0.35 & 3.6 & 0.003 \\
Model 2 (RV/TLC) ${ }^{\text {b }}$ & & $\beta^{\text {a }}$ & VIF & $p$ value \\
& LAV\% & 0.24 & 2.3 & 0.01 \\
& WA\% & -0.17 & 1.6 & 0.98 \\
& TAC & -0.17 & 3.2 & 0.14 \\
& AWV\% & -0.28 & 3.6 & 0.02 \\
\hline
\end{tabular}

area of the airways and large lung volume are major features of COPD and physiological studies have emphasized the importance of the relationship between airway and lung size in terms of structure-function, little attention has been paid to airway to lung volume ratio in COPD. Therefore, the present study is important as it established the AWV\% as a novel CT biomarker in COPD by showing that a reduction of AWV\% is significantly associated with lower $\mathrm{FEV}_{1}$ and higher RV/TLC independent of previously reported $\mathrm{CT}$ indices such as
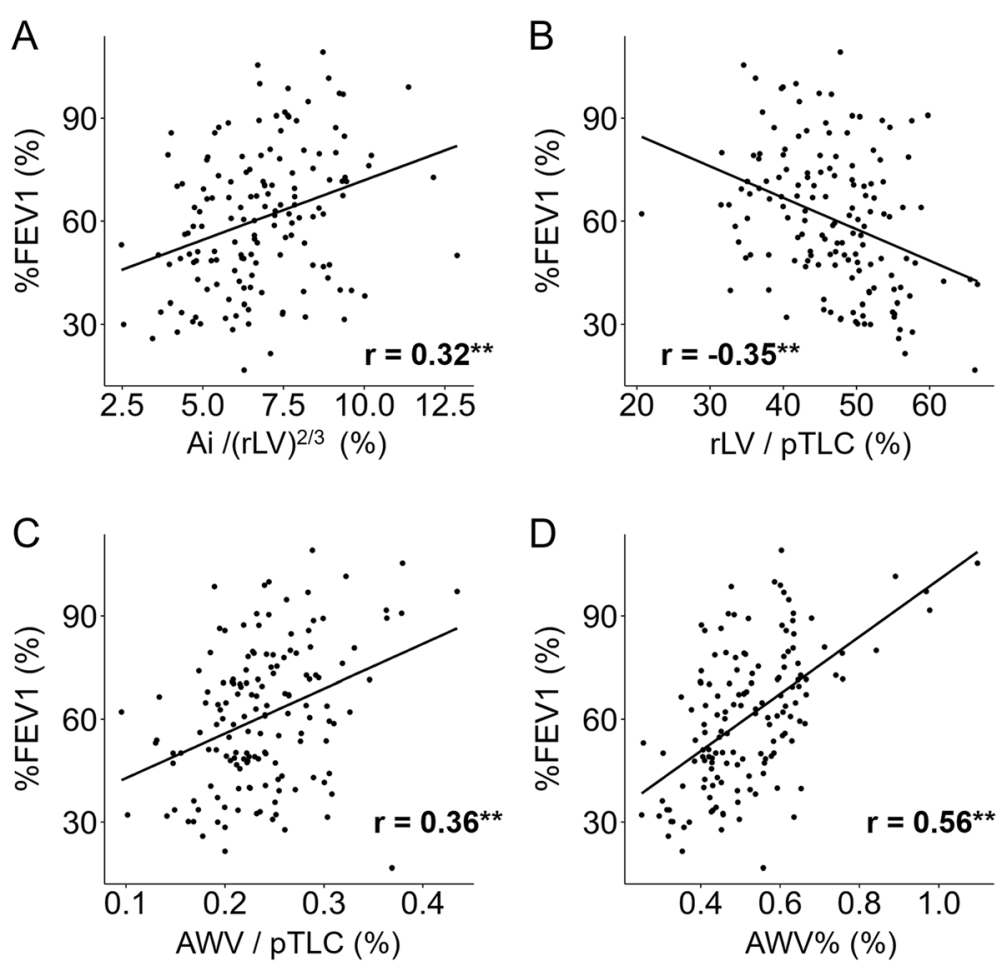

Fig. 3 Associations of airway size, lung volume, and airway to lung volume ratio with airflow obstruction. a Percentage ratio of lumen area of subsegmental airways (Ai) to cubic root squared right lung volume ( $\mathrm{rLV}$ ), b percentage ratio of rLV to predicted total lung capacity ( $p T L C)$, $\mathbf{c}$ percentage ratio of airway volume (AWV) to PTLC, and (d) airway volume percent (AW\%) were correlated with percentage of predicted forced expiratory volume in $1 \mathrm{~s}\left(\% \mathrm{FEV}_{1}\right)$. r value indicates the Pearson correlation coefficient. ${ }^{* *}$ indicates $p<0.005$ 
WA\%, LAV\%, and TAC. This suggests that a disproportionally small airway tree for a relatively large lung can be a major determinant of airflow obstruction and gas trapping.

The present finding that AWV\% is more closely correlated with $\% \mathrm{FEV}_{1}$ and $\mathrm{RV} / \mathrm{TLC}$ than simple measurement of lumen area, airway tree volume, and lung volume, as well as the ratio of lumen area to the cubic root squared right lung volume (Table 2), indicates the advantage of this new CT index. These results also confirm the concept that not only each structural change of airway and lung but also the interaction between these factors determines lung function. Because the visibility of airways on $\mathrm{CT}$ varies among individuals, it can be challenging to compare the lumen areas of spatially matched airways [36]. Thus, our findings suggest that the use of airway tree volume is more reasonable for assessment of airway size than that of lumen area.

The demographic data showing that $\% \mathrm{D}_{\mathrm{LCO}}$ was $53 \pm$ $14 \%$ and LAV\% was $29 \pm 9 \%$ suggest that the majority of the subjects had emphysema in this study. Parenchymal destruction of emphysema could increase lung volume through loss of elastic recoil and induce thoracic gas compression during forced expiration on spirometry [37]. Thus, the increased lung volume due to emphysema might have partially accounted for the close association between decreased AWV\% and FEV 1 .

In addition, considering that emphysema can be one of the causes of the airway volume reduction due to loss of alveolar attachments to the outer wall of the small airways [21, 22], one would hypothesize that lower AWV\% may be closely associated with higher LAV\%. However, the hypothesis is not well supported by the present data that showed the weak association between AWV\% and LAV\% $(r=-0.24)$ and no association between AWV\% and diffusion capacity. This might be because in addition to the impaired airway-parenchymal tethering due to emphysema, the luminal narrowing due to the mucus occlusion, bronchoconstriction, and wall remodeling may also contribute to the reduction in the airway volume measured on CT.

The results of multivariate analysis show that AWV\% was associated with airflow limitation and gas trapping independent of LAV\%, WA\%, and TAC. This finding suggest that in terms of assessment of the structure-function relationship, measuring the airway tree to lung volume ratio is complementary to measuring emphysematous change, impaired visibility of the airways and wall remodelling of the visible central airways, which are established CT findings in COPD lungs [14-17, 38].

The univariate and multivariate analysis (Table 2 and Table 3) show that both AWV\% and LAV\% had greater impacts on $\% \mathrm{FEV}_{1}$ and $\mathrm{RV} / \mathrm{TLC}$ than the other CT indexes. Furthermore, the statistical model including both AWV\% and LAV\% accounted for more variation of $\% \mathrm{FEV}_{1}\left(R^{2}=0.47\right)$ than the models including either AWV\% $\left(R^{2}=0.34\right)$ or LAV\% $\left(R^{2}=0.21\right)$. While emphysema is visually and quantitatively evaluated in clinical setting, the presence and severity of emphysema is not directly linked to airflow obstruction [39, 40], which is measured on spirometry for diagnosis of COPD. Thus, the present findings propose the potential clinical implication of AWV\% by showing that combining AWV\% to LAV\% may allow more accurate estimation of airflow obstruction than emphysema measurement alone. Furthermore, because AWV\% reflects both airway dimension and lung volume, and bronchodilation and lung deflation are main targets for standard therapy using long-acting bronchodilators in COPD [41], AWV\% might sensitively detect an effect of bronchodilator therapy. A future research is needed to test this possibility.

Abnormal lung growth has recently been proposed as a major contributor to COPD development [26]. Studies have shown that a variability in associations between airway and lung size due to dysanaptic lung growth in early life is associated with lung function [24, 25], and an increase in lung size without change in airway size due to chronic hypoxia at higher altitude is associated with poor lung function [9]. These findings raise the possibility that the present finding that lower AWV\% is correlated with lower $\mathrm{FEV}_{1}$ and higher RV/TLC might have been affected by abnormal lung growth. Whether the combined presence of smaller airways and larger lung is associated with the early onset of COPD should be examined in a future study.

With respect to clinical symptoms, the present study showed that the AWV\% was significantly lower in subjects with a CAT score $\geq 10$ than in those with a CAT score $<10$. We also performed multivariate logistic regression analysis to test whether a decrease in AWV\% was associated with the presence of symptoms after adjusting $\% \mathrm{FEV}_{1}$, age, BMI, smoking status, and CT-measured total lung volume but could not detect significant contribution of the AWV\% to symptoms (data not shown). Because clinical symptoms are influenced by multiple factors including not only airway disease but also emphysema and systemic comorbidities, such as cardiovascular disease and depression [42], a larger sample size would be necessary to clarify the relationship between the decreased AWV\% and symptoms. It might also be useful to apply a specific questionnaire for respiratory symptoms, such as Cough and Sputum Assessment Questionnaire (CASA-Q) [43].

Some limitations need to be described. First, because the lumen size is underestimated in smaller airways due to the resolution of CT $[12,44]$ and measurement of the $\mathrm{AWV} \%$ is based on the volumes of all visible airways, 
including these smaller airways, the AWV\% might be underestimated compared to the actual ratio of the airway volume to the lung volume. However, we think that the use of AWV\% is valid because the influence of this underestimation should be equally applied in all CT scans. Moreover, the fact that all the CT scans were obtained with one CT scanner under one condition increases the validity of the results. Second, the present study did not use both lungs for measurement of the AWV\% because cardiac motion artefacts could increase the measurement error for airway volume in the left lung. Finally, because all the included patients were male, and since the size of airways and extent of airway remodelling differ between males and females [45, 46], whether the present findings are applicable to female patients is unclear.

\section{Conclusions}

This study established a novel CT marker to evaluate airway tree to lung volume ratio, AWV\%, and showed that a disproportionately small airway tree volume for a given lung volume is associated with worsening of airflow obstruction and gas trapping. This index is a promising CT biomarker that is easily measured and allows for improved understanding of the interaction between airway disease and lung hyperinflation on lung function and clinical outcomes in COPD.

\section{Additional file}

Additional file 1: Figure S1 Examples of original $\mathrm{CT}$ images and segmentations of airway trees and all branches in the right lung. Figure S2 The airway volume percent in symptomatic and non-symptomatic subjects. Figure $\mathbf{S 3}$ Associations of the airway volume percent and low attenuation volume percent with physiological measurements. Figure S4 Associations of the airway volume percent with currently established CT indexes. Table S1 Multivariate regression models regarding pulmonary function. (PDF $514 \mathrm{~kb}$ )

\section{Abbreviations}

Ai: Airway lumen area; AWV: Airway volume; AWV\%: Airway volume percent; CAT: COPD Assessment Tests; COPD: Chronic obstructive pulmonary disease; $C T$ : Computed tomography; CT-TLV: Total lung volume measured on CT; $D_{\perp c o}$ : Diffusion capacity; FEV $V_{1}$ : Forced expiratory volume in $1 \mathrm{~s}$; HU: Hounsfield units; LAV\%: Low attenuation volume percent; pTLC: Predicted total lung capacity; rLV: Right lung volume; RV/TLC: Residual volume/total lung capacity; TAC: Total airway count

\section{Acknowledgements}

Not applicable

\section{Funding}

This work was funded by the Japan Society for the Promotion of Science (JSPS) [Grants-in-Aid for scientific research No. 17H06807] for the collection and analysis of data.

\section{Availability of data and materials}

The datasets used and/or analyzed during the current study are available from the corresponding author on reasonable request.

\section{Authors' contributions}

NT and SS analyzed and interpreted the CT data, and wrote the manuscript. $\mathrm{TO}, \mathrm{HS}, \mathrm{AS}$ and SM contributed to the conception and interpretation of the data. TH contributed to the interpretation of $\mathrm{CT}$ data and the editing of the manuscript. All authors read and approved the final manuscript.

\section{Authors' information}

Not applicable

\section{Ethics approval and consent to participate}

This study was performed in accordance with the Declaration of Helsinki. This human study was approved by the Ethics Committee of Kyoto University (approval No. E182). Written informed consent was obtained from all participants.

\section{Consent for publication}

Not applicable

\section{Competing interests}

NT, SM, SS, TO, AS, and TH were partially supported by a grant from FUJIFILM Medical in this work.

\section{Publisher's Note}

Springer Nature remains neutral with regard to jurisdictional claims in published maps and institutional affiliations.

Received: 2 December 2018 Accepted: 8 April 2019

Published online: 18 April 2019

\section{References}

1. Hogg JC. Pathophysiology of airflow limitation in chronic obstructive pulmonary disease. Lancet. 2004;364:709-21.

2. Lynch DA, Al-Qaisi MA. Quantitative computed tomography in chronic obstructive pulmonary disease. J Thorac Imaging. 2013;28:284-90.

3. Nakano Y, Muro S, Sakai H, Hirai T, Chin K, Tsukino M, Nishimura K, Itoh H, Pare PD, Hogg JC, Mishima M. Computed tomographic measurements of airway dimensions and emphysema in smokers. Correlation with lung function. Am J Respir Crit Care Med. 2000;162:1102-8.

4. Grydeland TB, Dirksen A, Coxson HO, Eagan TM, Thorsen E, Pillai SG, Sharma S, Eide GE, Gulsvik A, Bakke PS. Quantitative computed tomography measures of emphysema and airway wall thickness are related to respiratory symptoms. Am J Respir Crit Care Med. 2010;181:353-9.

5. Han MK, Kazerooni EA, Lynch DA, Liu LX, Murray S, Curtis JL, Criner GJ, Kim V, Bowler RP, Hanania NA, et al. Chronic obstructive pulmonary disease exacerbations in the COPDGene study: associated radiologic phenotypes. Radiology. 2011;261:274-82.

6. Haruna A, Muro S, Nakano Y, Ohara T, Hoshino Y, Ogawa E, Hirai T, Niimi A, Nishimura K, Chin K, Mishima M. CT scan findings of emphysema predict mortality in COPD. Chest. 2010;138:635-40.

7. Smith BM, Hoffman EA, Basner RC, Kawut SM, Kalhan R, Barr RG. Not all measures of hyperinflation are created equal: lung structure and clinical correlates of gas trapping and hyperexpansion in COPD: the multi-ethnic study of atherosclerosis (MESA) COPD study. Chest. 2014;145:1305-15.

8. Tanabe N, Muro S, Oguma T, Sato S, Kiyokawa H, Takahashi T, Kudo M, Kinose D, Kubo T, Hoshino Y, et al. Computed tomography assessment of pharmacological lung volume reduction induced by bronchodilators in COPD. COPD. 2012:9:401-8.

9. Llapur CJ, Martinez MR, Grassino PT, Stok A, Altieri HH, Bonilla F, Caram MM, Krowchuk NM, Kirby M, Coxson HO, Tepper RS. Chronic hypoxia accentuates Dysanaptic lung growth. Am J Respir Crit Care Med. 2016;194:327-32.

10. Rogers RM, Coxson HO, Sciurba FC, Keenan RJ, Whittall KP, Hogg JC. Preoperative severity of emphysema predictive of improvement after lung volume reduction surgery: use of CT morphometry. Chest. 2000;118:1240-7.

11. Coxson HO, Nasute Fauerbach PV, Storness-Bliss C, Muller NL, Cogswell S, Dillard DH, Finger CL, Springmeyer SC. Computed tomography assessment of lung volume changes after bronchial valve treatment. Eur Respir J. 2008; 32:1443-50.

12. Oguma T, Hirai T, Niimi A, Matsumoto H, Muro S, Shigematsu M, Nishimura T, Kubo Y, Mishima M. Limitations of airway dimension measurement on images obtained using multi-detector row computed tomography. PLoS One. 2013;8:e76381. 
13. Nakano Y, Wong JC, de Jong PA, Buzatu L, Nagao T, Coxson HO, Elliott WM, Hogg JC, Pare PD. The prediction of small airway dimensions using computed tomography. Am J Respir Crit Care Med. 2005;171:142-6.

14. Washko GR, Diaz AA, Kim V, Barr RG, Dransfield MT, Schroeder J, Reilly J J Ramsdell JW, McKenzie A, Van Beek EJ, et al. Computed tomographic measures of airway morphology in smokers and never-smoking normals. J Appl Physiol (1985). 2014;116:668-73.

15. Hasegawa M, Nasuhara $Y$, Onodera $Y$, Makita $H$, Nagai $K$, Fuke $S$, Ito $Y$, Betsuyaku T, Nishimura M. Airflow limitation and airway dimensions in chronic obstructive pulmonary disease. Am J Respir Crit Care Med. 2006;173: 1309-15.

16. Kirby M, Tanabe N, Tan WC, Zhou G, Obeidat M, Hague CJ, Leipsic J, Bourbeau J, Sin DD, Hogg JC, et al. Total airway count on computed tomography and the risk of chronic obstructive pulmonary disease progression. Findings from a population-based study. Am J Respir Crit Care Med. 2018;197:56-65.

17. Diaz AA, Valim C, Yamashiro T, Estepar RS, Ross JC, Matsuoka S, Bartholmai B, Hatabu H, Silverman EK, Washko GR. Airway count and emphysema assessed by chest $\mathrm{CT}$ imaging predicts clinical outcome in smokers. Chest. 2010;138:880-7.

18. Wilson AG, Massarella GR, Pride NB. Elastic properties of airways in human lungs post mortem. Am Rev Respir Dis. 1974;110:716-29.

19. Pare PD, Mitzner W. Airway-parenchymal interdependence. Compr Physiol. 2012;2:1921-35

20. Petty TL, Silvers GW, Stanford RE. Radial traction and small airways disease in excised human lungs. Am Rev Respir Dis. 1986;133:132-5.

21. Saetta M, Ghezzo H, Kim WD, King M, Angus GE, Wang NS, Cosio MG. Loss of alveolar attachments in smokers. A morphometric correlate of lung function impairment. Am Rev Respir Dis. 1985;132:894-900.

22. Tanabe N, Vasilescu DM, McDonough JE, Kinose D, Suzuki M, Cooper JD, Pare PD, Hogg JC. Micro-computed tomography comparison of Preterminal bronchioles in Centrilobular and Panlobular emphysema. Am J Respir Crit Care Med. 2017;195:630-8.

23. Diaz AA, Come CE, Ross JC, San Jose Estepar R, Han MK, Loring SH, Silverman EK, Washko GR, Investigators CO. Association between airway caliber changes with lung inflation and emphysema assessed by volumetric CT scan in subjects with COPD. Chest. 2012;141:736-44.

24. Mead J. Dysanapsis in normal lungs assessed by the relationship between maximal flow, static recoil, and vital capacity. Am Rev Respir Dis. 1980;121: 339-42.

25. Sheel AW, Guenette JA, Yuan R, Holy L, Mayo JR, McWilliams AM, Lam S, Coxson $\mathrm{HO}$. Evidence for dysanapsis using computed tomographic imaging of the airways in older ex-smokers. J Appl Physiol (1985). 2009;107:1622-8.

26. Lange $P$, Celli B, Agusti A, Boje Jensen G, Divo M, Faner R, Guerra S, Marott $J$, Martinez FD, Martinez-Camblor $P$, et al. Lung-function trajectories leading to chronic obstructive pulmonary disease. N Engl J Med. 2015;373:111-22.

27. Tanabe N, Muro S, Hirai T, Oguma T, Terada K, Marumo S, Kinose D, Ogawa E, Hoshino Y, Mishima M. Impact of exacerbations on emphysema progression in chronic obstructive pulmonary disease. Am J Respir Crit Care Med. 2011;183:1653-9.

28. Terada K, Muro S, Sato S, Ohara T, Haruna A, Marumo S, Kinose D, Ogawa E, Hoshino $Y$, Niimi A, et al. Impact of gastro-oesophageal reflux disease symptoms on COPD exacerbation. Thorax. 2008;63:951-5.

29. Yushkevich PA, Piven J, Hazlett HC, Smith RG, Ho S, Gee JC, Gerig G. User-guided 3D active contour segmentation of anatomical structures: significantly improved efficiency and reliability. Neuroimage. 2006;31: 1116-28.

30. Quanjer PH, Tammeling GJ, Cotes JE, Pedersen OF, Peslin R, Yernault JC. Lung volumes and forced ventilatory flows. Eur Respir J. 1993;6(Suppl 16):5-40.

31. Oguma T, Hirai T, Fukui M, Tanabe N, Marumo S, Nakamura H, Ito H, Sato S, Niimi A, Ito I, et al. Longitudinal shape irregularity of airway lumen assessed by $C T$ in patients with bronchial asthma and COPD. Thorax. 2015;70:719-24.

32. Tanabe N, Muro S, Sato S, Oguma T, Sato A, Hirai T. Fractal analysis of low attenuation clusters on computed tomography in chronic obstructive pulmonary disease. BMC Pulm Med. 2018;18:144

33. Tanabe N, Muro S, Tanaka S, Sato S, Oguma T, Kiyokawa H, Takahashi T, Kinose D, Hoshino Y, Kubo T, et al. Emphysema distribution and annual changes in pulmonary function in male patients with chronic obstructive pulmonary disease. Respir Res. 2012;13:31.

34. Tanabe N, Vasilescu DM, Kirby M, Coxson HO, Verleden SE, Vanaudenaerde BM, Kinose D, Nakano Y, Pare PD, Hogg JC. Analysis of airway pathology in
COPD using a combination of computed tomography, micro-computed tomography and histology. Eur Respir J. 2018:51:17205.

35. R Core Team: R: A Language and Environment for Statistical Computing. URL http://www.r-project.org/. 2015.

36. Smith BM, Hoffman EA, Rabinowitz D, Bleecker E, Christenson S, Couper D, Donohue KM, Han MK, Hansel NN, Kanner RE, et al. Comparison of spatially matched airways reveals thinner airway walls in COPD. The multi-ethnic study of atherosclerosis (MESA) COPD study and the subpopulations and intermediate outcomes in COPD study (SPIROMICS). Thorax. 2014;69:987-96.

37. Pellegrino R, Crimi E, Gobbi A, Torchio R, Antonelli A, Gulotta C, Baroffio M, Papa GF, Dellaca R, Brusasco V. Severity grading of chronic obstructive pulmonary disease: the confounding effect of phenotype and thoracic gas compression. J Appl Physiol (1985). 2015:118:796-802.

38. McDonough JE, Yuan R, Suzuki M, Seyednejad N, Elliott WM, Sanchez PG, Wright AC, Gefter WB, Litzky L, Coxson HO, et al. Small-airway obstruction and emphysema in chronic obstructive pulmonary disease. N Engl J Med. 2011;365:1567-75.

39. Makita H, Nasuhara Y, Nagai K, Ito Y, Hasegawa M, Betsuyaku T, Onodera Y, Hizawa N, Nishimura M, Hokkaido CCSG. Characterisation of phenotypes based on severity of emphysema in chronic obstructive pulmonary disease. Thorax. 2007;62:932-7.

40. Lutchmedial SM, Creed WG, Moore AJ, Walsh RR, Gentchos GE, Kaminsky DA. How common is airflow limitation in patients with emphysema on CT scan of the chest? Chest. 2015:148:176-84.

41. Hohlfeld JM, Vogel-Claussen J, Biller H, Berliner D, Berschneider K, Tillmann HC, Hiltl S, Bauersachs J, Welte T. Effect of lung deflation with indacaterol plus glycopyrronium on ventricular filling in patients with hyperinflation and COPD (CLAIM): a double-blind, randomised, crossover, placebocontrolled, single-Centre trial. Lancet Respir Med. 2018;6:368-78.

42. Karloh M, Fleig Mayer A, Maurici R, Pizzichini MMM, Jones PW, Pizzichini E. The COPD assessment test: what do we know so far?: a systematic review and meta-analysis about clinical outcomes prediction and classification of patients into GOLD stages. Chest. 2016:149:413-25.

43. Hasegawa K, Sato S, Tanimura K, Fuseya Y, Uemasu K, Hamakawa Y, Sato A, Mishima M, Muro S, Hirai T. Gastroesophageal reflux symptoms and nasal symptoms affect the severity of bronchitis symptoms in patients with chronic obstructive pulmonary disease. Respir Investig. 2018:56:230-7.

44. Pare PD, Nagano T, Coxson HO. Airway imaging in disease: gimmick or useful tool? J Appl Physiol (1985). 2012:113:636-46.

45. Martinez FJ, Curtis JL, Sciurba F, Mumford J, Giardino ND, Weinmann G, Kazerooni E, Murray S, Criner GJ, Sin DD, et al. Sex differences in severe pulmonary emphysema. Am J Respir Crit Care Med. 2007;176:243-52.

46. Dominelli PB, Ripoll JG, Cross TJ, Baker SE, Wiggins CC, Welch BT, Joyner MJ. Sex differences in large conducting airway anatomy. J Appl Physiol (1985). 2018;125:960-5

\section{Ready to submit your research? Choose BMC and benefit from:}

- fast, convenient online submission

- thorough peer review by experienced researchers in your field

- rapid publication on acceptance

- support for research data, including large and complex data types

- gold Open Access which fosters wider collaboration and increased citations

- maximum visibility for your research: over $100 \mathrm{M}$ website views per year

At BMC, research is always in progress.

Learn more biomedcentral.com/submissions 